\title{
Raf-1 oncogenic signaling is linked to activation of mesenchymal to epithelial transition pathway in metastatic breast cancer cells
}

\author{
ALEXEY A. LEONTOVICH ${ }^{1,4}$, SHUYA ZHANG $^{1}$, COSIMA QUATRARO $^{1}$, IANKO IANKOV $^{3}$, \\ PIER FRANCESCO VEROUX ${ }^{7}$, MARIO W. GAMBINO ${ }^{1}$, AMY DEGNIM $^{5}$, JAMES MCCUBREY ${ }^{6}$, \\ JAMES INGLE $^{2}$, EVANTHIA GALANIS ${ }^{2,3}$ and ANTONINO B. D'ASSORO ${ }^{1}$ \\ Departments of ${ }^{1}$ Biochemistry and Molecular Biology, ${ }^{2}$ Medical Oncology and ${ }^{3}$ Molecular Medicine, \\ ${ }^{4}$ Division of Biomedical Statistics and Informatics, ${ }^{5}$ Department of General Surgery, Mayo Clinic College of Medicine, \\ 200 First Street SW, Rochester, MN; ${ }^{6}$ Department of Microbiology and Immunology, Brody School of Medicine \\ at East Carolina University, Greenville, NC, USA; ${ }^{7}$ Department of Surgery, Transplantation and \\ Advanced Technologies, Organ Transplant Unit and Vascular Surgery, University of Catania, Italy
}

Received December 15, 2011; Accepted January 23, 2012

DOI: 10.3892/ijo.2012.1407

\begin{abstract}
Aberrant activation of the Raf/MEK/MAPK pathway plays a key role in breast cancer development and progression. Dysregulation of Raf/MEK/MAPK oncogenic signaling often results from overexpression of the HER-2/Neu tyrosine kinase receptor leading to chemoendocrine resistance, development of distant metastases and ultimately poor prognosis in breast cancer patients. HER-2/Neu overexpression is also linked to activation of the epithelial to mesenchymal transition (EMT) pathway, loss of adhesion molecules and metastasis. Recently, it has been demonstrated that cancer cells that undergo EMT acquire a CD $44^{+} / \mathrm{CD} 24 \%$ low basal cancer stem cell-like phenotype and are characterized by activation of HER-2/Neu and TGF $\beta$ oncogenic signaling pathways with increased capacity of self-renewal, drug resistance, invasion and distant metastases. Following metastatic dissemination, cancer cells re-activate certain epithelial properties through mesenchymal to epithelial transition (MET) to establish neoplastic lesions at secondary sites, although the molecular mechanisms regulating MET remain elusive. In this study we demonstrate that constitutive activation of Raf-1 oncogenic signaling induces HER-2/Neu overexpression leading to the development of distant metastases in $\mathrm{ER} \alpha^{+} \mathrm{MCF}-7$ breast cancer xenografts. Importantly, development of distant metastases in xenograft models was linked to activation of the MET pathway characterized by reduced expression of EMT inducer genes (TGFB2, TWIST1 and FOXC1) and overexpression of BMB7, CXCR7 and EGR family of transcription factors. In
\end{abstract}

Correspondence to: Dr Antonino B. D'Assoro, Department of Biochemistry and Molecular Biology, Mayo Clinic College of Medicine, 200 First Street SW, Rochester, MN, USA

E-mail: dassoro.antonio@mayo.edu

Key words: Raf-1, breast cancer, Raf/MEK/MAPK pathway, HER-2/ Neu, tyrosine kinase receptor summary, our results demonstrate for the first time that amplification of Raf/MEK/MAPK oncogenic signaling during tumor growth promotes the genesis of metastatic lesions from primary tumors by activating the mesenchymal epithelial transition.

\section{Introduction}

Each year more than 210,000 new cases of breast cancer are diagnosed in the USA (1). More than two-thirds of these patients display initially positivity for the estrogen receptor $(\mathrm{ER} \alpha)$ making them eligible for endocrine therapy (2). Usually $E R \alpha^{+}$ breast tumors show a better outcome compared to ER $\alpha^{-}$tumors because they display a more differentiated epithelial phenotype, are sensitive to endocrine therapy and show a moderately invasive behavior (3). Tamoxifen has been the most widely used adjuvant anti-estrogen agent for the past two decades, achieving a $39 \%$ reduction in disease recurrence and a $31 \%$ reduction in mortality in ER $\alpha$ early stage breast carcinomas (4). Despite the clinical benefit of hormonal treatment in patients with $\mathrm{ER} \alpha^{+}$ breast cancer, primary and secondary resistance to endocrine therapy remains a significant clinical problem (5). One of the molecular mechanisms by which $\mathrm{ER} \alpha^{+}$breast tumors become resistant to endocrine manipulations is through overexpression of the receptor tyrosine kinase HER-2/Neu (6-8). Overexpression of HER-2/Neu signaling pathway induces phosphorylation and constitutive activation of $\mathrm{ER} \alpha$ leading to aberrant cell proliferation $(9,10)$. HER-2/Neu is overexpressed in $20-30 \%$ of invasive breast tumors and is associated with poor clinical outcome with reduced disease-free and overall survival rates $(11,12)$. Cellular plasticity occurs in cancer progression in a similar fashion of embryonic development. The importance of cellular transitions in development is first apparent during gastrulation when the process of epithelial to mesenchymal transition (EMT) transforms polarized epithelial cells into migratory mesenchymal cells that constitute the embryonic and extra-embryonic mesoderm (13). It is now widely accepted that this developmental pathway is exploited in various disease states, including cancer. The loss of epithelial characteristics and the acquisition of a 
mesenchymal-like migratory phenotype that characterize EMT are crucial to the development of invasive carcinomas and metastasis (14).

Metastatic dissemination is an extremely complex and highly organized process that is organ-specific and involves numerous reciprocal interactions between the cancer cells and the host (15). Breast cancer progression is dependent on the capacity to metastasize to distant organs, and loss of cancer cell adhesion through EMT plays a key role in this process $(16,17)$. Importantly, HER-2/ Neu overexpression is linked to loss of the adhesion molecule E-cadherin during breast cancer progression, dissemination and metastasis (18). However, given the morphological similarities between primary tumor and metastatic lesions, it is likely that tumor cells re-activate certain epithelial properties through a mesenchymal to epithelial transition (MET) at the secondary site, although the molecular mechanisms regulating MET pathway remain elusive (19).

One of the major problems in eradicating metastatic cancer cells consists in their ability to self-renewal and to display higher resistance to conventional chemo-endocrine therapy $(20,21)$. Recently, the discovery that breast tumors contain a CD $44^{+} / \mathrm{CD} 24$ /low sub-population of cells harboring stem cell properties has generated excitement because these cancer stem cells may represent the source of therapeutic failures, distant metastases and ultimately poor outcome (22-24). It has also been demonstrated that cancer cells that undergo EMT acquire a basal cancer stem cell-like phenotype and display increased expression of the enzyme aldehyde dehydrogenase (ALDH) increasing tumorigenicity, chemoresistance and invasiveness $(25,26)$. Moreover, tumors enriched with cancer stem cells are characterized by activation of HER-2/Neu and TGF $\beta$ oncogenic signaling pathways with increased capacity of self-renewal, drug resistance, invasion and distant metastases $(27,28)$. Transcription factors such as TWIST1, SNAIL, SLUG, FOXC1, ZEB1 and SMADs play a key role in orchestrate the nuclear reprogramming leading to activation of EMT and stemness of cancer cells (29-31).

In this study we have employed an $\mathrm{ER} \alpha^{+} \mathrm{MCF}-7$ breast cancer cell line engineered to express constitutive active Raf-1 oncoprotein to characterize the role of aberrant Raf/ MEK/MAPK signaling pathway in breast cancer progression. Our results demonstrate that constitutive activation of Raf-1 confers a more aggressive phenotype characterized by increased cell proliferation and migration, chemo-endocrine resistance and ultimately development of distant metastases. Importantly, development of distant metastases in xenograft models was linked to overexpression of HER-2/Neu and activation of MET pathway leading to the establishment of secondary neoplastic lesions. Taken together, our results demonstrate for the first time that amplification of Raf/MEK/ MAPK oncogenic signaling during tumor growth promotes the genesis of metastatic lesions from primary breast cancer cells by activating MET signaling.

\section{Materials and methods}

Human breast cancer cell lines. The human breast cancer cell line MCF-7 was obtained from ATCC (Manassas, VA, USA). The MCF-7 cells overexpressing the Raf-1 oncoprotein were generated as described previously (32). All cell lines were maintained in EMEM medium containing $5 \mathrm{mM}$ glutamine, $1 \%$ penicillin/streptomycin, $20 \mathrm{microgram}$ insulin $/ \mathrm{ml}$ and $10 \% \mathrm{FBS}$ at $37^{\circ} \mathrm{C}$ in $5 \% \mathrm{CO}_{2}$ atmosphere.

Cell proliferation assay. For cell proliferation assay, breast cancer cells were cultured in a 96-well plate at a density of 2,000 cells in each plate and treated with $1 \mu \mathrm{m}$ daunorubicin (Sigma). Following a 7-day incubation, cell viability was determined using the CellTiter $96^{\circledR}$ Aqueous One Solution Cell Proliferation Assay (Promega, Madison, WI, USA), performed according to the manufacturer's protocol.

Cell cycle profile, indirect immunofluorescence and immunoblotting. For fluorescence-activated cell sorting (FACS), Indirect immunofluorescence and protein expression analyses, breast cancer cells were treated as previously described (33-35).

Antibodies. Antibodies employed in this study were the following: Cell Signaling Technology (tMAPK, p-MAPK, HER-2/Neu, E-cadherin); Santa Cruz Biotechnology (ER $\alpha)$ and Sigma ( $\beta$-actin).

In vitro cell migration assay. In vitro migration assay of MCF-7 and vMCF-7 ${ }^{\text {Raf-1 }}$ cells was performed by employing the xCELLigence System (Roche) according to the manufacturer's procedure.

Human breast cancer xenografts. Procedures established by the Institutional Animal Care and Use Committee based on US NIH guidelines for the care and use of laboratory animals were followed for all experiments. Four-week-old non-ovariectomized female $\mathrm{NCR} / \mathrm{Nu} / \mathrm{Nu}$ nude mice were anesthetized by exposure to $3 \%$ isoflurane and injected subcutaneously with $2 \times 10^{6}$ cells suspended in $50 \mu$ of $50 \%$ Matrigel (BD Bioscience, Bedford, MA, USA). Tumor localization and growth was monitored using the IVS imaging system from the ventral view $10 \mathrm{~min}$ after luciferin injection. After 12 weeks, mice were sacrificed and xenograft tumors were processed for histology, immunohistochemistry and immunofluorescence analyses as previously described $(34,35)$. To re-establish cultures from $1 \mathrm{GX}$ explants, tumors were excised from the animals, minced using sterile scissors, transferred to complete culture medium and fibroblast-free tumor cell lines were established by serial passages in culture.

Gene microarray analysis. Total RNA was extracted from breast cancer cells using TRizol according to the manufacturer's instructions (Invitrogen, Carlsbad, CA). One microgram of total RNA (A260/A280 ratio of 1.8-2.2) was used to probe for global genome expression employing Affimetrix U133 Plus 2.0 chips (Affimetrix, Santa Clara, CA). The raw data (CEL files) were pre-processed using GCRMA algorithm using Partek GS 6.5 software (St. Louis, MO). Partek built in tools were used to perform analysis of variance (ANOVA) on groups of samples. Experiments were performed in duplicates.

\section{Results and Discussion}

To characterize the mechanistic role of aberrant activation of MAPK signaling pathway in breast cancer progression, we 


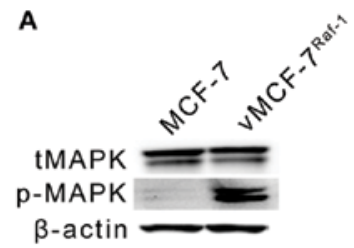

C
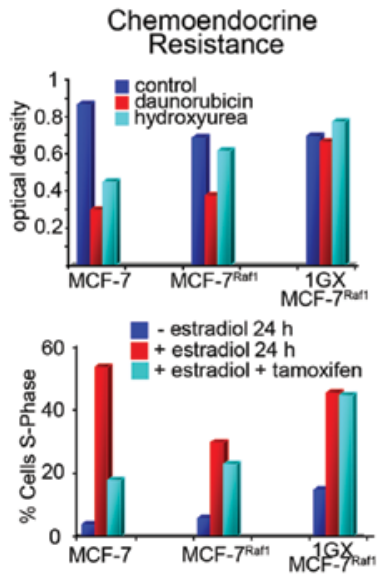

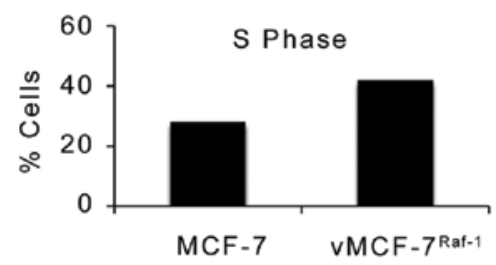

D

Real Time Cell Migration Assay

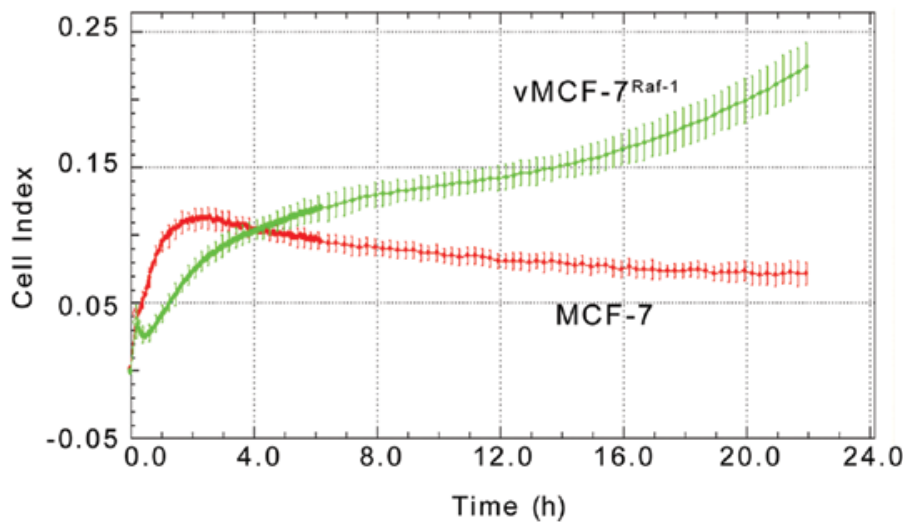

Figure 1. Molecular characterization of MCF-7 cells harboring constitutive activation of Raf/MEK/MAPK pathway. (A) Immunoblot assay showing MAPK phosphorylation in vMCF-7 ${ }^{\Delta R a f-1}$ compared to parental MCF-7 cells. (B) Cell cycle analysis (FACS) showing increased S phase fraction in vMCF-7 ${ }^{\Delta R a f-1}$ compared to parental MCF-7 cells. (C) MTT assay and FACS analysis of variants and parental MCF-7 cells treated with chemo-endocrine therapy. (D) Real-time cell migration assay showing higher motility of vMCF-7 ${ }^{\triangle \mathrm{Raf}-1}$ compared to parental MCF-7 cells.

A

Tumor Xenografts

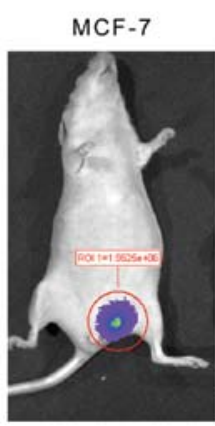

VMCF-7RAF-1

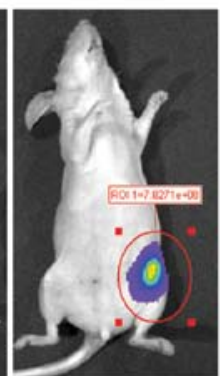

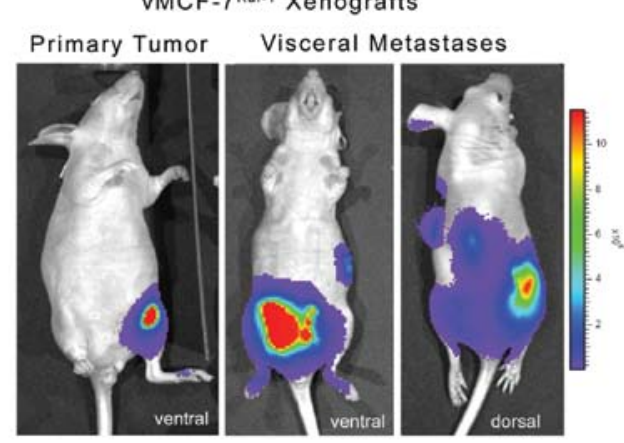

c

HER2/Neu Immunohistochemistry

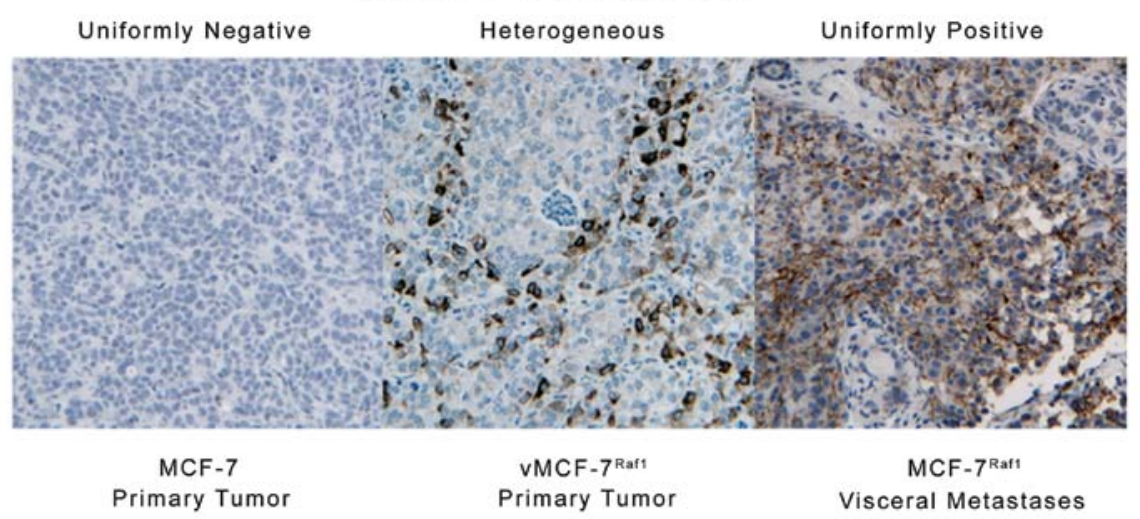

Figure 2. Establishment of MCF-7 and vMCF-7 ${ }^{\Delta R a f-1}$ breast cancer xenografts. (A) Tumor imaging in live animals of MCF-7 and vMCF-7 $7^{\Delta R a f-1}$ xenografts expressing the firefly luciferase reporter lenti-vector at 4 weeks after mammary fat pad injection. (B) Tumor imaging in live animals of vMCF-7 ${ }^{\text {Raf-1 }}$ xenografts expressing the firefly luciferase reporter lenti-vector at 12 weeks after mammary fat pad injection and 8 weeks following surgical removal. (C) Paraffin sections of xenograft tumors showing expression of HER-2 receptor in primary and metastatic vMCF-7 $7^{\text {Raf-1 }}$ xenografts. 
employed a variant MCF-7 cell line overexpressing a constitutive active Raf-1 oncoprotein (vMCF-7 ${ }^{\Delta \text { Raf-1 }}$ ) as previously described (32). Hyper-phosphorylation of MAPK demonstrated constitutive activation of Raf/MEK/MAPK pathway in $v M C F-7^{\triangle \mathrm{Raf}-1}$ compared to parental MCF-7 cells (Fig. 1A). To determine the extent to which aberrant Raf/MEK/MAPK signaling pathway confers an advantage on cell cycle progression, we performed a FACS cell cycle analysis on MCF-7 and vMCF-7 ${ }^{\Delta \text { Raf- } 1}$ cells. vMCF-7 $7^{\Delta \text { Raf-1 }}$ displayed a higher percentage of cells in the $\mathrm{S}$ phase fraction of the cell cycle compared to parental MCF-7 cells, indicating that constitutive MAPK activation accelerates G1/S cell cycle progression (Fig. 1B). Since aberrant activation of Raf/MEK/MAPK signaling pathway is linked to increased chemo-endocrine resistance in breast cancer, we treated MCF-7 and vMCF-7 ${ }^{\triangle \text { Raf-1 }}$ cells with anti-cancer drugs targeting the DNA replication process (hydroxyurea and daunorubicin) and ER $\alpha$ mitogenic pathway (tamoxifen). Resistance to chemo-endocrine treatment was observed in $\mathrm{vMCF}-7^{\Delta \mathrm{Raf}-1}$ compared to parental MCF-7 cells, indicating that aberrant Raf/MEK/MAPK signaling activation induced chemo-endocrine resistance in estrogensensitive breast cancer cells (Fig. 1C). Since tumor progression and development of distant metastases is linked to increased cell motility and consequent invasion, we employed an innovative real-time migratory assay to establish whether constitutive Raf/ MEK/MAPK signaling activation conferred higher motility properties of MCF-7 cells. Importantly, vMCF-7 ${ }^{\triangle \mathrm{Raf}-1}$ cells showed a higher migration index than MCF-7 cells during a 24-h migration assay (Fig. 1D) suggesting that activation of Raf-1 signaling pathway promotes an invasive phenotype. To determine in vivo the extent to which vMCF-7 ${ }^{\Delta \text { Raf-1 }}$ cells gave rise to invasive breast tumors, we established murine MCF-7 and vMCF-7 $7^{\Delta \text { Raf-1 }}$ xenografts (Fig. 2). vMCF-7 ${ }^{\Delta \text { Raf-1 }}$ xenografts developed larger tumors than parental MCF-7 xenografts following a 4-week cancer cells injection into the mammary fat pad (Fig. 2A). Breast tumors were surgically removed 12 weeks after implantation without sacrificing the animals to monitor the development of distant metastases (Fig. 2B). Significantly, 8 weeks following surgical removal, only vMCF- $7^{\triangle \text { Raf- }^{\prime}}$ xenografts developed frank visceral metastases demonstrating that aberrant Raf/MEK/MAPK signaling pathway induces metastatic dissemination (Fig. 2B). Because development of chemo-endocrine resistance and distant metastases is often associated to HER-2/Neu overexpression in breast cancer, we performed immunohistochemistry analysis of HER-2/Neu staining on primary tumors and metastatic lesions (Fig. 2C). While MCF-7 primary tumors did not show positivity for HER-2/Neu, vMCF-7 ${ }^{\Delta R a f-1}$ primary tumors displayed HER-2/ Neu heterogeneity and vMCF-7 ${ }^{\Delta \text { Raf-1 }}$ metastatic tumors showed strong positivity for HER-2/Neu expression. These results demonstrate that aberrant Raf/MEK/MAPK pathway induces HER-2/Neu expression during tumor growth, suggesting a key role of HER-2 oncogenic signaling pathway in the development of breast cancer metastases and tumor progression. Furthermore, to characterize the molecular mechanisms responsible for the development of distant metastases in vMCF- $7^{\text {Raf-1 }}$ xenografts, we re-cultured cancer cells from MCF-7 and vMCF-7 ${ }^{\Delta \text { Raf-1 }}$ xenografts (primary and metastatic) and termed them first generation xenografts (1GX). Immunoblot analysis revealed that primary and metastatic vMCF-7 ${ }^{\triangle \text { Raf-1 }} 1 \mathrm{GX}$ cells overexpressed ER $\alpha$ compared to parental cells (Fig. 3A). However primary vMCF-7 $7^{\Delta \text { Raf-1 }} 1 \mathrm{GX}$ cells displayed higher resistance to chemo-endocrine therapy
(Fig. 1C) indicating that aberrant activation of Raf-1/MEK/ MAPK pathway and HER-2/Neu overexpression activates ER $\alpha$ pathway and confers higher resistance to conventional anti-cancer therapy during in vivo growth. To establish the extent to which development of breast cancer metastases was linked to EMT, we analyzed the expression of key EMT markers (E-cadherin and $\beta$-catenin) in breast cancer cells. Loss of E-cadherin expression was observed in MCF-7 $1 \mathrm{GX}$ and vMCF-7 ${ }^{\Delta \text { Raf- } 1} 1 \mathrm{GX}$ cells while cultured MCF-7, vMCF-7 ${ }^{\text {Raf-1 }}$ and metastatic vMCF-7 ${ }^{\text {Raf-1 }} 1 G X$ cells expressed high levels of E-cadherin. Similarly, expression of the epithelial marker $\beta$-catenin was increased in MCF-7, MCF-7 $1 \mathrm{GX}$ and metastatic vMCF-7 ${ }^{\triangle \mathrm{Raf}-1} 1 \mathrm{GX}$ cells compared to its expression level in vMCF-7 $7^{\Delta \text { Raf- } 1}$ and vMCF-7 $7^{\Delta \text { Raf- } 1} 1 G X$ cells (Fig. 3A). Immunofluorescence analysis also demonstrated that metastatic vMCF-7 ${ }^{\Delta \mathrm{Raf}-1} 1 \mathrm{GX}$ cells re-express the epithelial markers E-cadherin and $\beta$-catenin compared to primary vMCF-7 ${ }^{\Delta \text { Raf-1 }} 1 \mathrm{GX}$ cells (Fig. 3B). These results demonstrate that HER-2/Neu overexpression and amplification of MAPK signaling pathway in vMCF-7 ${ }^{\Delta \text { Raf-1 }}$ xenografts induces development of EMT and metastatic dissemination, while re-expression of epithelial markers and activation of MET pathway is essential for the establishment of secondary neoplastic lesions. To determine whether activation of EMT and MET pathways during in vivo growth of vMCF-7 ${ }^{\Delta \mathrm{Raf}-1}$ cells were linked to specific transcriptome changes that are critical for tumor progression, we employed human Affimetrix micro-arrays to assess global gene expression of breast cancer cells (Fig. 4A). From this comparison, we identified a group of 8 differentially expressed genes involved in tumor growth (TGFB2, BMB7, EGR2, EGR3, EGR4), EMT (TWIST1, FOXC1) and metastasis (CXCR7) correlated with tumor progression (Fig. 4B-D). Specifically, TGFB2 and CXCR7 genes were overexpressed in the metastatic vMCF-7 ${ }^{\Delta \text { Raf-1 }} 1 \mathrm{GX}$ cells while BMP7 gene was down-regulated compared to the primary vMCF-7 $7^{\triangle \mathrm{Raf}-1} 1 \mathrm{GX}$ cells (Fig. 4B). These results indicate that TGFB2 and BMP7 signaling pathways are positive and negative regulators of distant metastases in breast cancer, respectively. Furthermore, we identified genes encoding for nuclear transcription factors involved in the induction of EMT such as TWIST1 and FOXC1 that were down-regulated in metastatic vMCF- $7^{\Delta \text { Raf-1 }} 1 \mathrm{GX}$ compared to primary vMCF-7 ${ }^{\triangle \mathrm{Raf}-1} 1 \mathrm{GX}$ cells (Fig. $4 \mathrm{C}$ ). These findings substantiate suppression of EMT, activation of MET pathway and consequent re-expression of epithelial markers observed in metastatic vMCF-7 ${ }^{\Delta \text { Raf-1 }} 1 \mathrm{GX}$ cells compared to primary tumors (Fig. 3). Importantly, vMCF-7 ${ }^{\triangle \mathrm{Raf}-1} 1 \mathrm{GX}$ cells that lack epithelial markers displayed a decreased expression of EGR2, EGR3 and EGR4 nuclear transcription factors compared to $\mathrm{MCF}-7$, vMCF-7 ${ }^{\Delta \mathrm{Raf}-1}$ and metastatic vMCF-7 ${ }^{\Delta \mathrm{Raf}-1} 1 \mathrm{GX}$ cells that expressed high levels of E-cadherin and $\beta$-catenin (Fig. 4D). These results highlight a novel role for the EGR family of transcription factors in the activation of MET pathway and establishment of breast cancer metastases.

Taken together these findings demonstrate that constitutive activation of Raf-1 oncoprotein leads to HER-2/Neu overexpression and consequent amplification of MAPK signaling pathway during breast cancer progression. Importantly, metastatic spreading to distant organs is characterized by activation of EMT pathway and loss of E-cadherin and $\beta$-catenin epithelial markers during tumor growth. Activation of MET pathway and re-expression of epithelial markers is essential for 
A

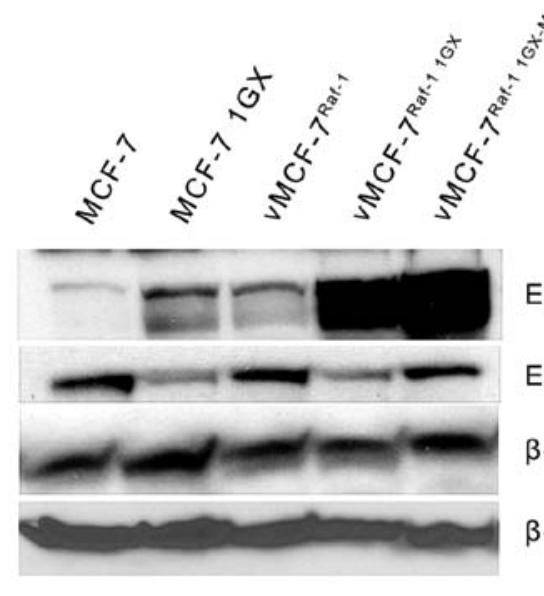

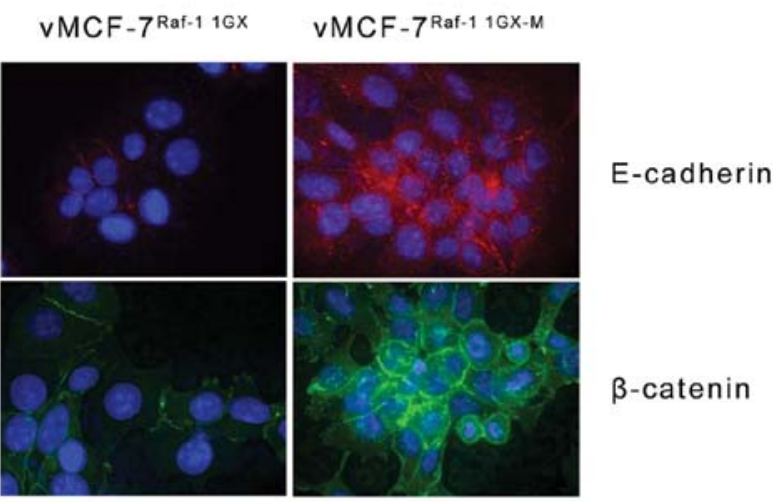

Figure 3. Characterization of EMT in human breast cancer cell lines. (A) Immunoblot assay showing expression of ER $\alpha$, E-cadherin and $\beta$-catenin proteins in variants and parental MCF-7 cells. (B) Immunofluorescence analysis showing expression of E-cadherin and $\beta$-catenin in metastatic vMCF-7 $7^{\Delta R a f-1} 1 G X$ cells.

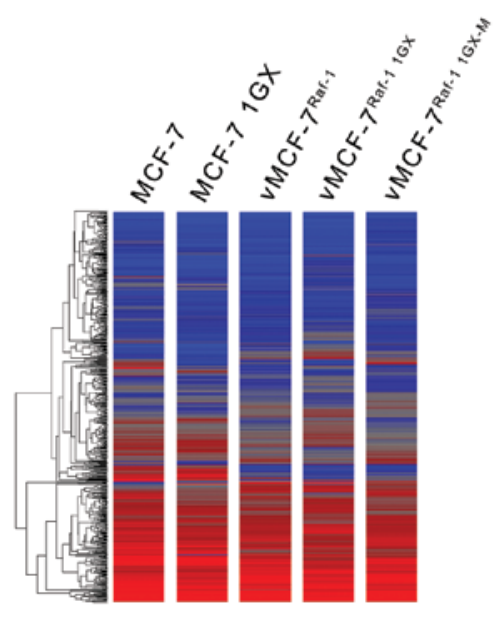

C

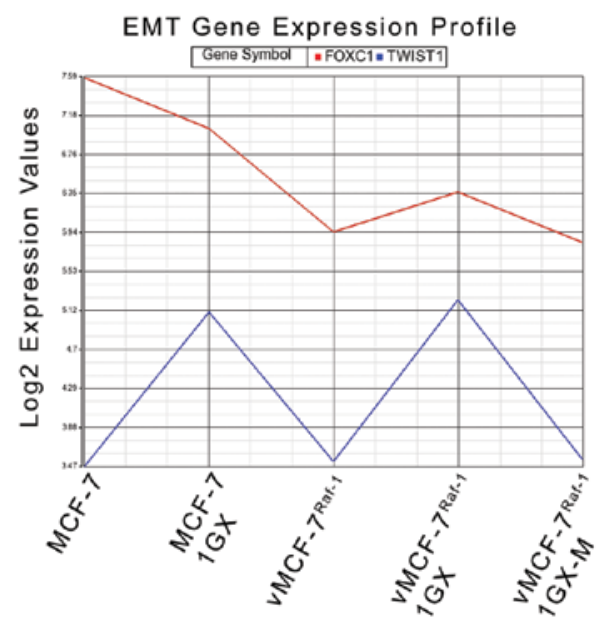

B

TGFB2/BMP7/CXCR7 Gene Expression Profile

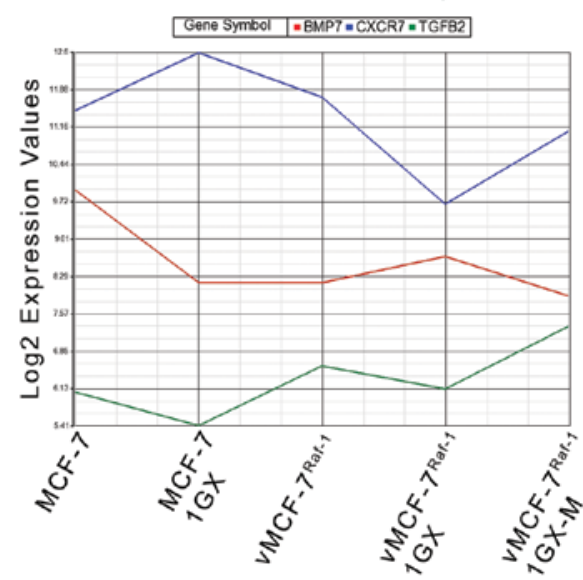

D

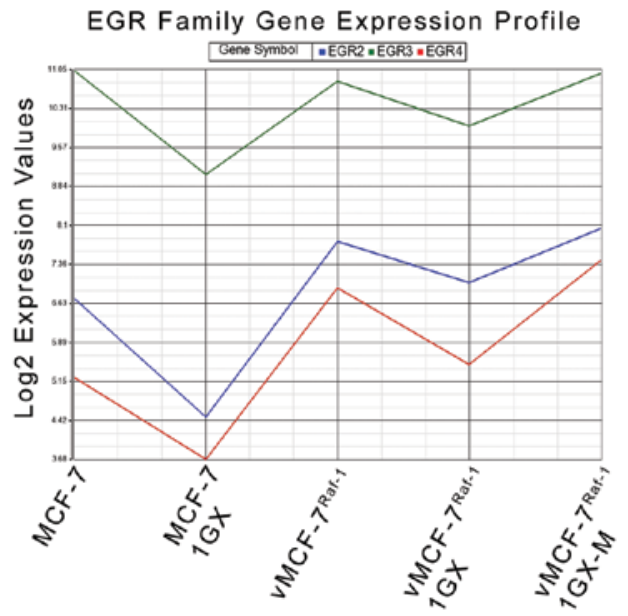

Figure 4. Global gene expression profile in human breast cancer cell lines. (A) Heat map representing the unsupervised cluster analysis of global gene expression of MCF-7, MCF-7 1GX, vMCF-7 $7^{\wedge \text { Raf-1 }}$, vMCF-7 ${ }^{\wedge \text { Raf-1 }} 1 \mathrm{GX}$ and metastatic vMCF-7 ${ }^{\mathrm{Raf}-1} 1 \mathrm{GX}$ cells. (B-D) Expression profile of TGFB2, BMP7, CXCR7, FOXC1, TWIST1, EGR2, EGR3 and EGR4 genes in MCF-7, MCF-7 1GX, vMCF-7 ${ }^{\Delta \text { Raf-1 }}$, vMCF-7 ${ }^{\text {Raf-1 }} 1 \mathrm{GX}$ and metastatic vMCF-7 ${ }^{\Delta \text { Raf-1 }} 1 \mathrm{GX}$ cells. 
the establishment of secondary neoplastic lesions. Activation of MET signaling is characterized by reduced expression of EMT inducer genes (TGFB2, TWIST1 and FOXC1) and overexpression of BMB7, CXCR7 and EGR family of transcription factors. In conclusion, this study highlighted for the first time the mechanistic linkage between Raf/MEK/MAPK oncogenic signaling and development of distant metastases through activation of MET pathway.

\section{Acknowledgements}

This study was supported by USAMRMC BC02276, the Intramural RECDA Award and the Mayo Clinic Breast Cancer Specialized Program of Research Excellence NIH CA116201 to ABD, and the Mayo Clinic School of Medicine. We also wish to acknowledge the TACMA and CTSA facilities for performing the immunohistochemistry and gene microarray assays and assisting us with the interpretation of the results.

\section{References}

1. Jemal A, Siegel R, Xu J and Ward E: Cancer statistics. CA Cancer J Clin 60: 277-300, 2010.

2. Li CI, Daling JR and Malone KE: Incidence of invasive breast cancer by hormone receptor status from 1992 to 1998. J Clin Oncol 21: 28-34, 2003.

3. Colleoni M, Sun Z, Martinelli G, Basser RL, Coates AS, Gelber RD, Green MD, Peccatori F, Cinieri S, Aebi S, Viale G, Price KN and Goldhirsch A: The effect of endocrine responsiveness on high-risk breast cancer treated with dose-intensive chemotherapy: results of International Breast Cancer Study Group Trial 15-95 after prolonged follow-up. Ann Oncol 20: 1344-1351, 2009.

4. Early Breast Cancer Trialists' Collaborative Group (EBCTCG): Effects of chemotherapy and hormonal therapy for early breast cancer on recurrence and 15-year survival: an overview of the randomised trials. Lancet 365: 1687-1717, 2005.

5. Ring A and Dowsett M: Mechanisms of tamoxifen resistance. Endocr Relat Cancer 11: 643-658, 2004.

6. Leung E, Kannan N, Krissansen GW, Findlay MP and Baguley BC: MCF-7 breast cancer cells selected for tamoxifen resistance acquire new phenotypes differing in DNA content, phospho-HER2 and PAX2 expression, and rapamycin sensitivity. Cancer Biol Ther 9: 717-724, 2010.

7. Johnston S, Pippen J Jr, Pivot X, Lichinitser M, Sadeghi S, Dieras V, Gomez HL, Romieu G, Manikhas A, Kennedy MJ, Press MF, Maltzman J, Florance A, O'Rourke L, Oliva C, Stein S and Pegram M: Lapatinib combined with letrozole versus letrozole and placebo as first-line therapy for postmenopausal hormone receptor-positive metastatic breast cancer. J Clin Oncol 27: 5538-5546, 2009.

8. Hurtado A, Holmes KA, Geistlinger TR, Hutcheson IR, Nicholson RI, Brown M, Jiang J, Howat WJ, Ali S and Carroll JS Regulation of ERBB2 by oestrogen receptor-PAX2 determines response to tamoxifen. Nature 456: 663-666, 2008.

9. Ghayad SE, Vendrell JA, Ben Larbi S, Dumontet C, Bieche I and Cohen PA: Endocrine resistance associated with activated ErbB system in breast cancer cells is reversed by inhibiting MAPK or PI3K/Akt signaling pathways. Int J Cancer 126: $545-562,2010$.

10. Massarweh S, Osborne CK, Creighton CJ, Qin L, Tsimelzon A, Huang S, Weiss H, Rimawi M and Schiff R: Tamoxifen resistance in breast tumors is driven by growth factor receptor signaling with repression of classic estrogen receptor genomic function. Cancer Res 68: 826-833, 2008.

11. Bartlett AI, Starcyznski J, Robson T, Maclellan A, Campbell FM, van de Velde CJ, Hasenburg A, Markopoulos C, Seynaeve C, Rea D and Bartlett JM: Heterogeneous HER2 gene amplification: impact on patient outcome and a clinically relevant definition. Am J Clin Pathol 136: 266-274, 2011

12. Al-Azawi D, Leong S, Wong L, Kay E, Hill AD and Young L: HER-2 positive and 553 negative breast cancers are associated with poor prognosis. Cancer Invest 29: 365-369, 2011.
13. Acloque $\mathrm{H}$, Ocaña $\mathrm{OH}$, Matheu A, Rizzoti K, Wise C, Lovell-Badge R and Nieto MA: Reciprocal repression between Sox 3 and snail transcription factors defines embryonic territories at gastrulation. Dev Cell 21: 546-558, 2011.

14. Thiery JP, Acloque H, Huang RY and Nieto MA: Epithelialmesenchymal transitions in development and disease. Cell 139: 871-890, 2009.

15. Gupta GP and Massagué J: Cancer metastasis: building a framework. Cell 127: 679-695, 2006.

16. Foroni C, Broggini M, Generali D and Damia G: Epithelialmesenchymal transition and breast cancer: role, molecular mechanisms and clinical impact. Cancer Treat Rev, Nov 25, 2011 (E-pub ahead of print).

17. Takebe N, Warren RQ and Ivy SP: Breast cancer growth and metastasis: interplay between cancer stem cells, embryonic signaling pathways and epithelial-to-mesenchymal transition. Breast Cancer Res 13: 211, 2011.

18. Freudenberg JA, Wang Q, Katsumata M, Drebin J, Nagatomo I and Greene MI: The role of HER2 in early breast cancer metastasis and the origins of resistance to HER2-targeted therapies. Exp Mol Pathol 87: 1-11, 2009.

19. Armstrong AJ, Marengo MS, Oltean S, Kemeny G, Bitting RL, Turnbull JD, Herold CI, Marcom PK, George DJ and GarciaBlanco MA: Circulating tumor cells from patients with advanced prostate and breast cancer display both epithelial and mesenchymal markers. Mol Cancer Res 9: 997-1007, 2011.

20. Scopelliti A, Cammareri P, Catalano V, Saladino V, Todaro M and Stassi G: Therapeutic implications of cancer initiating cells. Expert Opin Biol Ther 9: 1005-1016, 2009.

21. Kurrey NK, Jalgaonkar SP, Joglekar AV, Ghanate AD, Chaskar PD, Doiphode RY and Bapat SA: Snail and slug mediate radioresistance and chemoresistance by antagonizing p53-mediated apoptosis and acquiring a stem-like phenotype in ovarian cancer cells. Stem Cells 27: 2059-2068, 2009.

22. Shipitsin M, Campbell LL, Argani P, Weremowicz S, BloushtainQimron N, Yao J, Nikolskaya T, Serebryiskaya T, Beroukhim R, Hu M, Halushka MK, Sukumar S, Parker LM, Anderson KS, Harris LN, Garber JE, Richardson AL, Schnitt SJ, Nikolsky Y, Gelman RS and Polyak K: Molecular definition of breast tumor heterogeneity. Cancer Cell 11: 259-273, 2007.

23. Ahmed MA, Aleskandarany MA, Rakha EA, Moustafa RZ, Benhasouna A, Nolan C, Green AR, Ilyas M and Ellis IO: A CD44(-)/CD24 (+) phenotype is a poor prognostic marker in early invasive breast cancer. Breast Cancer Res Treat, Nov 27, 2011 (E-pub ahead of print).

24. Olsson E, Honeth G, Bendahl PO, Saal LH, Gruvberger-Saal S, Ringnér M, Vallon-Christersson J, Jönsson G,Holm K, Lövgren K, Fernö M, Grabau D, Borg A and Hegardt C: CD44 isoforms are heterogeneously expressed in breast cancer and correlate with tumor subtypes and cancer stem cell markers. BMC Cancer 11: 418,2011

25. Croker AK and Allan AL: Inhibition of aldehyde dehydrogenase (ALDH) activity reduces chemotherapy and radiation resistance of stem-like ALDH(hi)CD44 (+) human breast cancer cells. Breast Cancer Res Treat, Aug 5, 2011 (E-pub ahead of print).

26. Reuben JM, Lee BN, Gao H, Cohen EN, Mego M, Giordano A, Wang X, Lodhi A, Krishnamurthy S, Hortobagyi GN, Cristofanilli M, Lucci A and Woodward WA: Primary breast cancer patients with high risk clinicopathologic features have high percentages of bone marrow epithelial cells with ALDH activity and CD44+/CD24low/- cancer stem cell phenotype. Eur J Cancer 47: 1527-1536, 2011.

27. Mani SA, Guo W, Liao MJ, Eaton EN, Ayyanan A, Zhou AY, Brooks M, Reinhard F, Zhang CC, Shipitsin M, Campbell LL, Polyak K, Brisken C, Yang J and Weinberg RA: The epithelialmesenchymal transition generates cells with properties of stem cells. Cell 133: 704-715, 2008.

28. Korkaya H, Paulson A, Iovino F and Wicha MS: HER2 regulates the mammary stem/progenitor cell population driving tumorigenesis and invasion. Oncogene 27: 6120-6130, 2008.

29. Soini Y, Tuhkanen H, Sironen R, Virtanen I, Kataja V, Auvinen P, Mannermaa A and Kosma VM: Transcription factors zeb1, twist and snail in breast carcinoma. BMC Cancer 11: 73, 2011.

30. Al Saleh S, Sharaf LH and Luqmani YA: Signalling pathways involved in endocrine resistance in breast cancer and associations with epithelial to mesenchymal transition. Int J Oncol 38: 1197-1217, 2011.

31. Labelle M, Begum S and Hynes RO: Direct signaling between platelets and cancer cells induces an epithelial-mesenchymal-like transition and promotes metastasis. Cancer Cell 20: 576-590, 2011. 
32. Davis JM, Navolanic PM, Weinstein-Oppenheimer CR Steelman LS, Hu W, Konopleva M, Blagosklonny MV and McCubrey JA: Raf-1 and Bcl-2 induce distinct and common pathways that contribute to breast cancer drug resistance. Clin Cancer Res 9: 1161-1170, 2003.

33. D'Assoro AB, Barrett SL, Folk C, Negron VC, Boeneman K, Busby R, Whitehead C, Stivala F, Lingle WL and Salisbury JL: Amplified centrosomes in breast cancer: a potential indicator of tumor aggressiveness. Breast Cancer Res Treat 75: 25-34, 2002.

34. D'Assoro AB, Busby R, Suino K, Delva E, AlmodovarMercado GJ, Johnson H, Folk C, Farrugia DJ, Vasile V, Stivala F and Salisbury JL: Genotoxic stress leads to centrosome amplification in breast cancer cell lines that have an inactive G1/S cell cycle checkpoint. Oncogene 23: 4068-4075, 2004.
35. D'Assoro AB, Busby R, Acu ID, Quatraro C, Reinholz MM, Farrugia DJ, Schroeder MA, Allen C, Stivala F, Galanis E and Salisbury JL: Impaired p53 function leads to centrosome amplification, acquired ERalpha phenotypic heterogeneity and distant metastases in breast cancer MCF-7 xenografts. Oncogene 27: 3901-3911, 2008. 